\title{
JEUX VIDÉO AU PORTUGAL. LISBONNE : FCA
}

VIDEOJOGOS EM PORTUGAL. LISBOA : FCA

\section{Liliana Costa Zagalo}

\section{(2) OpenEdition}

\section{Journals}

Édition électronique

URL : http://journals.openedition.org/ctd/2070

DOI : $10.4000 /$ ctd. 2070

ISSN : 2491-1437

\section{Éditeur}

Chaire Unesco Pratiques émergentes en technologies et communication pour le développement

Édition imprimée

Date de publication : 12 novembre 2015

\section{Référence électronique}

Liliana Costa Zagalo, «JEUX VIDÉO AU PORTUGAL. LISBONNE : FCA », Communication, technologies et développement [En ligne], 2 | 2015, mis en ligne le 12 juin 2019, consulté le 22 juillet 2020. URL : http:// journals.openedition.org/ctd/2070 ; DOI : https://doi.org/10.4000/ctd.2070

Ce document a été généré automatiquement le 22 juillet 2020.

Communication, technologies et développement 


\title{
JEUX VIDÉO AU PORTUGAL. LISBONNE : FCA
}

VIDEOJOGOS EM PORTUGAL. LISBOA : FCA

\author{
Liliana Costa Zagalo
}

1 Em "Videojogos em Portugal", o autor Nelson Zagalo deixa ao leitor uma herança relativamente ao ingresso de Portugal na indústria dos videojogos. Desengane-se quem pense que o livro apenas elenca o que foi feito a nível nacional e tampouco se trata de um livro sobre o passado. De facto, Zagalo estabelece o diálogo entre gerações de alguns protagonistas desta história e através da recolha dos seus testemunhos, trilha um percurso, nem sempre pacífico, na criação e desenvolvimento de videojogos.

2 De 1970 a 2012, a narrativa desenrola-se em oito capítulos, desde o Nascimento dos Videojogos, os Pioneiros Nacionais [1970-1990], passando por Do MS-DOS ao CD-Rom [1990-2004], Criação da Comunidade Nacional [1998-...], Fase Móvel [2002-2006] e O Mundo Online [2003-...] até à Entrada nas Consolas [2008-...] e A Nova Distribuição [2009-...].

3 A interação entre o homem e a máquina bem como a inteligência artificial têm despertado, ao longo do tempo, o interesse da sociedade. O Capítulo 1 - Nascimento dos Videojogos contextualiza a obra no panorama internacional desde os estudos de Wiener sobre cibernética ; a apresentação do jogo Tennis for Two em 1958; a competição entre Baer e Bushnell pelo jogo Pong; a extensão da ficção científica para o jogo espacial Spacewar; o processamento e armazenamento de informação em microprocessadores; a introdução do ZX Spectrum e o despoletar dos primeiros movimentos de criação e alteração de videojogos.

4 O Capítulo 2 - Os Pioneiros Nacionais [1970-1990] é dedicado à fase embrionária dos videojogos no contexto português. Num período em que o primeiro computador português (ENER 1000) é implementado e os microcomputadores são introduzidos em Portugal, emergem os primeiros videojogos com "nacionalidade" portuguesa. $\mathrm{O}$ autor narra a história de José oliveira, um jovem que em 1981 recria o jogo do galo para calculadora a partir do qual a sua curiosidade seria a alavanca para a criação dos jogos 
LASER e BALA. Outros jogos surgiram desde então, assumindo diferentes géneros nomeadamente, a aventura gráfica, jogos para adultos e gestão de equipas de futebol.

5 Apesar de não ter sido referenciado em nenhum dos testemunhos como é que o crash norte-americano da indústria de videojogos que decorreu de 1983 a 85 foi sentido no contexto português, é patente ao longo deste capítulo a escolha por outras plataformas (ex.: calculadora, ZX Spectrum) em alternativa ao desenvolvimento de jogos para a ATARI. De facto, a turbulência que se fazia sentir no momento, em que o mercado dos videojogos começava a ficar saturado, despoletou uma enorme recessão.

O jogo Extra-Terrestrial E.T lançado pela ATARI no Natal de 82 continua a ser lembrado como o símbolo de um fracasso (Wolf, 2012) sem precedentes pelo que se sugere que este tenha sido causado, entre outros fatores, por: (a) tentar reproduzir, num período de tempo muito limitado, uma experiência que igualasse a "experiência ótima" (Csikszentmihalyi, 1990) que a audiência já tinha tido com outro medium (filme); (b) não envolver o público-alvo quer na fase concepção ou teste do jogo, o que causou um desfasamento entre o modelo concetual do jogador e a complexidade do jogo e; (b) não reconhecer e garantir a exclusividade dos designers no processo, o que levou a que muitos produzissem os seus próprios jogos.

7 Este crash gera novas potencialidades no desenvolvimento de videojogos e o lançamento da Nintendo Entertainment Systems bem como a emergência do ZX Spectrum e da Commodore acabam por fazer com que os videojogos intervenham fortemente no espaço doméstico. A indústria dos videojogos é então relançada por criadores de jogos independentes e acredito que este movimento tenha inspirado, ainda que inconscientemente, os desenvolvedores de jogos portugueses.

8 As diferentes tipologias de jogos nacionais também acabam por espelhar os jogos introduzidos a nível internacional como as aventuras gráficas de Donkey Kong em 1980, a aventura gráfica Legenda de Zelda em 1986 ou até mesmo os jogos para adultos como o Leisure Suit Larry. É de realçar que ao longo do livro pode-se verificar uma clara influência dos jogos internacionais nas convenções utilizadas pelos jogos nacionais (ex.: Presença de um vilão, avatar, divisão em níveis, vista em perspectiva, tipologia de jogos, Elementos de ecrã de jogo (HUDs) como a colecção de itens - armas, feitiços, sistemas de combate, tipo de conflito,...). Esta semelhança com o que era produzido internacionalmente pode ser também reflexo do código disponível e bibliotecas de programação que eram partilhadas. Porém, verifica-se, ao longo do tempo, uma predominância das convenções dos jogos internacionais e a falta da influência da cultura nacional sobre este medium (que apenas se tem manifestado em alguns casos nos jogos educacionais em termos da narrativa).

9 O autor Zagalo lembra ainda que em Portugal, os jogos "foram considerados uma categoria menor" (p.36). É curioso verificar que este facto também ocorreu em Portugal quando na mesma época, este problema se estendia a outros países. Por exemplo, nas Filipinas os videojogos foram proibidos pelo presidente Marcos e as pessoas eram obrigadas a entregar os jogos às autoridades policiais ou até mesmo o caso do jogo Barbarian - The Ultimate Warrior (1987) que foi proibido na Alemanha pelo conteúdo sangrento. Denota-se, assim, o papel crucial que os jogos têm vindo a assumir como artefactos culturais e que a sua produção resultava de um hobby, reflexo da sua importância atribuída pela sociedade.

$10 \mathrm{Na}$ década de 90 em que se inicia o acesso generalizado dos computadores, surgem os jogos Doom e Myst que vêm dar um novo alento à indústria de videojogos, introduzindo 
novos elementos como o jogo em rede, a narrativa ou a imersão num mundo ficcional. Do MS-DOS ao CD-Rom reflecte uma época em que o ambiente gráfico dos jogos torna-se mais próximo do real e em que a fase do CD-Rom motivou fortemente a criação de jogos de aprendizagem como A Viagem de Bartolomeu Dias, As Aventuras da Peregrinação, Vasco da Gama : A Grande Viagem, Portugal 1111, entre outros.

11 A Criação da Comunidade Nacional ocorre anos mais tarde, quando se procede a uma pulverização da cultura de modding (alteração de software) e a criação de motores de jogo. As equipas True Dimensions e Gamelords dão os primeiros passos enquanto que o fórum GameDev-PT gera comunidades de prática, convidando à participação e partilha de conhecimentos(Howard, 2010; Pearce, Boellstorff, \& Nardi, 2011; Preece, 2000). Estas comunidades reúnem também a Academia que marca presença em eventos (como por exemplo, as conferências de Videojogos promovidas pela Sociedade Portuguesa dos Videojogos - SPCV).

12 Na Fase do móvel, o jogo volta a sair do espaço privado para o espaço público. Numa época em que há uma diluição do tempo e do espaço, os videojogos não só se prolongam na mente do jogador após a experiência, como também passam a estar acessíveis em qualquer momento em qualquer local. A permanência da interação é uma realidade e a identificação espacial que caracteriza as plataformas móveis dá lugar a novas tipologias de jogo - jogos baseados na localização que a empresa portuguesa Ydreams abordou desde cedo.

13 A estrutura reticular das relações entre indivíduos da sociedade (Castells,2002) é também transportada para os videojogos (Costa, 2013). No momento em que aparecem no panorama internacional, os títulos Ultima Online (1997), EverQuest (1999), Sims (2000) e World of Warcraft (2004) que conectam milhares de jogadores, o fenómeno em rede e a componente social são alvo dos jogos de empresas nacionais como a Ework Studios, Ignite Games, Real Time Solutions e BlitPop.

Em 2008, algumas empresas conquistam o mercado das consolas (ex.: jogos da Nintendo da Biodroid e a Seed Studios) e em 2009, a distribuição de jogos em novas plataformas (ex.: Mercado da App Store) teve também impacto na produção nacional pelo que há uma forte aposta de jogos nacionais no Miniclip Portugal, Steam ou Facebook.

O livro poderia terminar neste último capítulo com A Nova Distribuição, à semelhança de vários livros que se limitam aos fatores de sucesso. $\mathrm{O}$ autor optou por não o fazer $\mathrm{e}$ por essa razão é que afirmo que o mesmo deixa ao leitor uma herança no sentido em que nos apresenta alguns casos que falharam e promove a reflexão sobre alguns aspectos a considerar no desenvolvimento de jogos como: (a) a integração de equipas multidisciplinares e a (b) delineação de estratégias e modelos de distribuição e marketing eficazes. Porém, acrescem-se outras medidas que podem ajudar a relançar e fortalecer a indústria dos videojogos a nível nacional, como: (c) envolver o público-alvo no processo de conceção e teste dos artefactos (Costa, 2013; Veloso, 2006); (d) tornar os jogos acessíveis a diferentes públicos-alvo e ter em conta questões de usabilidade e acessibilidade e; (e) transportar a identidade portuguesa (através da música, literatura, cinema...) para o ambiente de jogo e introduzir novos produtos no mercado que possam marcar a diferença.

16 É de salientar ainda que poucos têm sido os livros (ex.: Grand Thieves \& Tomb Raiders: How British Video Games Conquered the World (Levene, \& Anderson, 2012); Libro blanco del desarrollo español de los videojuegos (DEV Associación Española de Empresas Productoras y Desarroladoras de Videojuegos y Software de Entretenimento, 
n.d); L'histoire des jeux video en France: 40 anos de news retro (Sanchez, 2014); PowerUp: How Japanese Video Games Gave The World An Extra Life (Kohler, 2004)) que abordam o posicionamento de um país face à história dos videojogos pelo que estas publicações são cada vez mais importantes para compreender os jogos enquanto artefacto que reflecte a identidade e cultura de uma sociedade. Neste sentido, importa compreender as influências internacionais na criação dos videojogos nacionais bem como a exportação de conceitos de jogo nacionais.

Por fim, termino afirmando que 'Videojogos em Portugal' é uma fonte de inspiração para os que querem fazer história, os que querem inovar, os que não têm medo de arriscar, os criativos e os que estão preparados para o grande desafio.

\section{BIBLIOGRAPHIE}

Referências

Castells, M. (2012). A Sociedade em Rede. S.Paulo: Ed.Paz e Terra. ISBN : 85-219-0329-4

Costa, L. (2013). Networked video games for older adults. Tese de Mestrado em Comunicação Multimédia. Universidade de Aveiro. Acedido em fevereiro 24, 2015, http://hdl.handle.net/ $10773 / 11326$

Csikszentmihalyi, M. (1990). Flow : The Psychology of Optimal Experience. HarperCollins. ISBN : 978-0-06-154812-3

DEV Associácion Española de Empresesas Productoras y Desarolladoras de Videojuegos y Software de Entretenimento. Libro Blanco del Desarrolo Español de los Videojuegos. Acedido fevereiro 24, 2015, em http://cercles.vtlseurope.com:8098/arxius/pdf/E140109.pdf

Howard, T. (2009). Design to thrive : Creating social networks and online communities that last. Morgan Kaufmann.ISBN:978-0-12-374921-5

Kohler, C. (2004). Power-Up : How Japanese Video Games Gave the World an Extra Life. BradyGames. ISBN : 978-0744004243

Levene, R., \& Anderson, M. (2012). Grand thieves \& Tomb Raiders : How British video games conquered the world. Aurum Press Limited. 978-1845137045

Pearce, C., Boellstorff, T., \& Nardi, B. A. (2011). Communities of play : Emergent cultures in multiplayer games and virtual worlds. MIT Press. ISBN : 978-0-262-16257-9

Preece, J. (2000). Online communities : Designing usability and supporting sociability. John Wiley \& Sons, Inc. ISBN : 0471805998

Sanchez, Frédéric (2014). L'histoire des jeux video en France. Editions RetroLand. ISBN : 978-2954947808

Veloso, A.I (2006). As tecnologias da comunicação e da informação nas brincadeiras das crianças. Tese de Doutoramento em Ciências e Tecnologias da Comunicação. Universidade de Aveiro. Acedido em fevereiro 24, 2015, http://hdl.handle.net/10773/11326 
Wolf, M. J. (2012). Before the crash : early video game history. Wayne State University Press. ISBN: 978-0814334508 